\title{
DIGITIZATION OF OBJECTS OF CULTURAL HERITAGE OF VARNA, PRODUCED IN THE STUDIO ARCHITECTURAL SPIES IN THE PERIOD 2013-2019
}

\section{Nadya Stamatova}

\begin{abstract}
This publication focuses on creating a database of $3 D$ models for an augmented reality mobile application allowing the visualization of the past condition of cultural heritage buildings in the real environment of the city of Varna, some of them no longer present in cityscape.

Keywords: digitization, digitalization, archaeology, $3 D$ models, heritage, cultural heritage, photogrammetry, augmented reality, virtual reality, $3 D, A R, V R, M R, M A R, X R, C H$
\end{abstract}

This publication presents the results of training young professionals and students to obtain practical skills in digitization of the cultural and historical heritage. The paper presents the result of the seven-year period from 2013 to 2019 of the digitization work in the R\&D SME Architectural Spies and the architectural studio Architectural Space under the mentorship of the architect Dr. Nadya Stamatova of young architects and engineers on the international programs Erasmus, Leonardo da Vinci, Cornelius Hertling, Erasmus+, and the national program Students' Internships of the Ministry of the Science and Education of Republic of Bulgaria. Young specialists from Italy, Turkey, Poland, Spain, Germany, Cyprus, Romania, and Kyrgyzstan have taken part in the above-mentioned international programs [14]. The Bulgarian national program provided the opportunity of training students from the Varna Free University, the Technical University - Varna, and the University of Architecture, Construction and Geodesy [14].

Significant methodological and scientific support was received from the academic supervisor of the trainees from the Technical University - Varna, the engineer of industrial design Assoc. Prof. Dr. T. Dovramadzhiev [7], as well from the academic supervisors from

Varna Free University: the academic supervisors D. Hristova $[8,9,10]$, a specialist of industrial archaeology and Dr. J. Ilieva [11], a specialist of cultural heritage.

Three papers on the previous digitization works of the studio already have been included in the volume №1 and volume №2 of the journal Digitization of the Cultural-Historical Heritage, an issue of the National Center for Digitization of the Balkans, Black Sea Region and Caucasus $[1,2,3]$, as well the $3 \mathrm{D}$ models of two statues of Nike [4, 5] and one of Heracles [6].

The first of the three publications mentioned above reveals to the general public the difficult start of digitizing in the studio Architectural Spies objects of the cultural heritage. This has a close connection with the work of Dr. N. Stamatova on the digital reconstruction of the Imperial Roman Thermae of the ancient Odessos according to the sketches and the hand drawings, provided by Prof. Dr. Stefan Boyadzhiev [12, 13], the eminent architect, specialized in archaeology.

Since the work of creating the digital model of the Roman baths was not funded by anyone, the project was going slowly, starting from 2006 and was worked on only during the periods when the studio had no specific architectural or contracted scientific tasks.
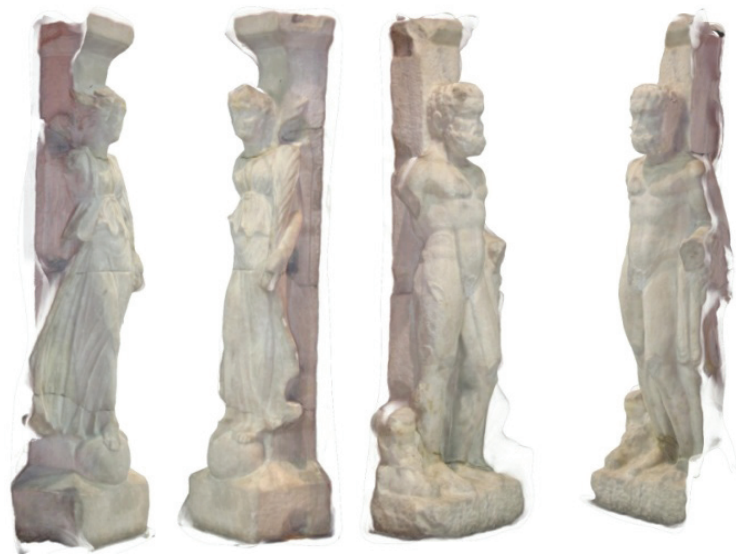

Fig. 1. Digital 3D models of statues of Nike and Heracles done by the software 123D Catch with removed background before processing.

Trainee: Teodora Yordanova, 2013 


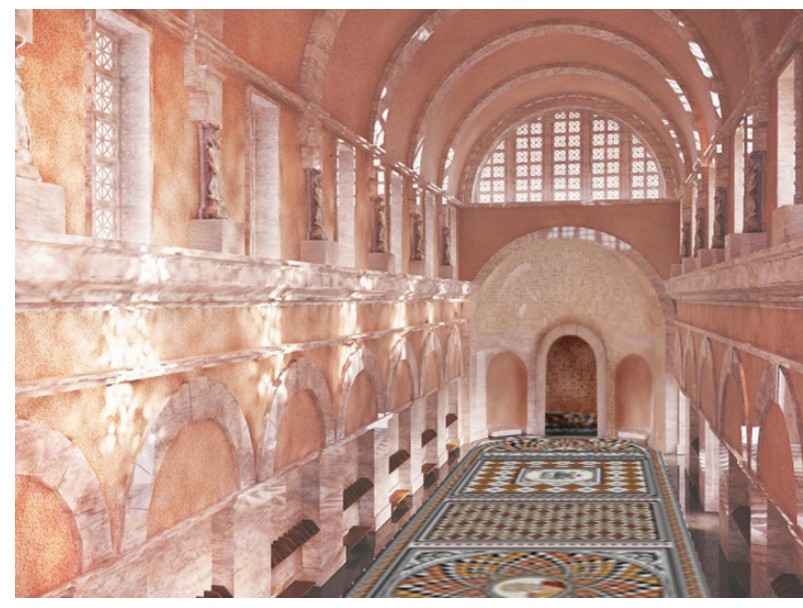

Fig. 2. 3D model of the interior of the biggest hall of the Imperial Roman Thermae of the ancient Odessos; 3D model: Miroslav Kostadinov, Floor mosaics: Inna Koleva Statues: Teodora Yordanova, 2014

The team started to work with photogrammetric software in 2013 thanks to the knowledge gained by Dr. N. Stamatova from the course on creating virtual museums, organized for professionals from South-East Europe in the capital of Bosnia and Herzegovina, Sarajevo. That same year Prof. Boyadzhiev passed away. Despite his advanced age (92), he was giving irreplaceable advice on the creation of the digital reconstruction of the Roman thermae until the end of his life (Zheleva-Martins D.[12]).
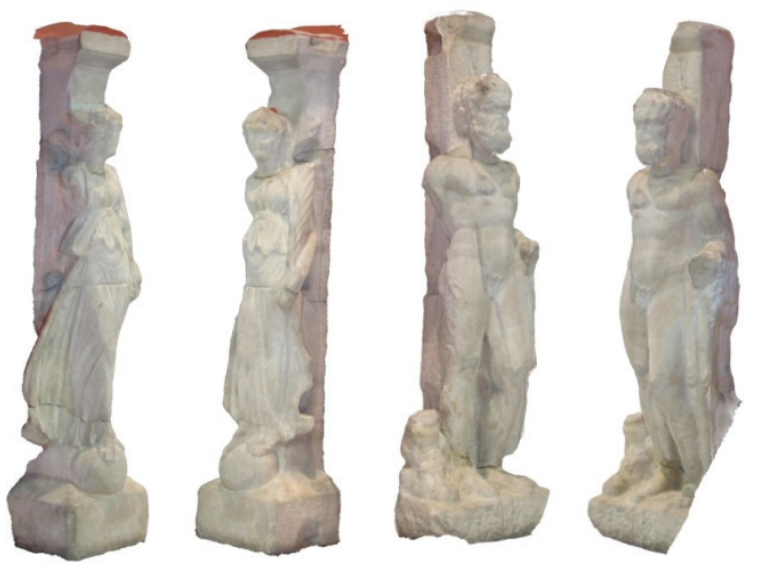

Fig. 3. Digital 3D models of statues of Nike and Heracles done by the software ReCap with removed background after processing. Trainee: Teodora Yordanova, 2018

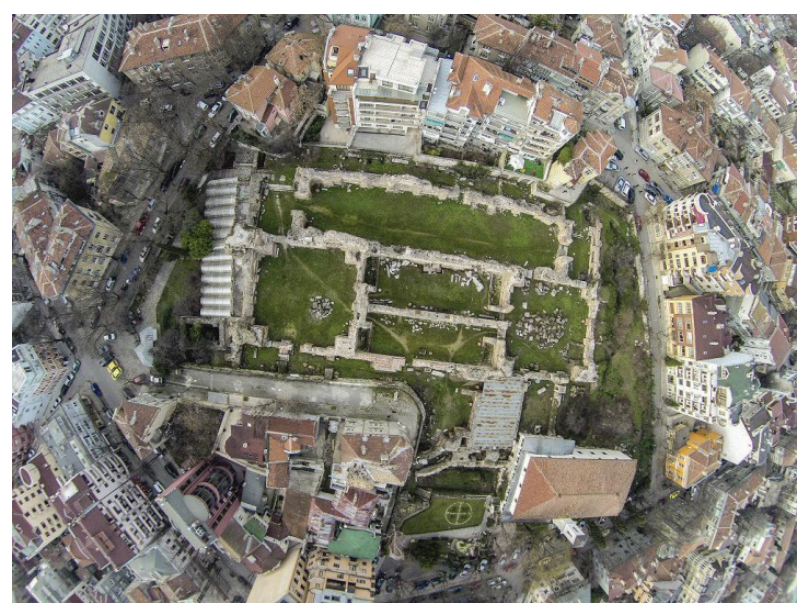

Fig. 4. Aerial photography at the ruins of the archaeological site of the Imperial Roman Thermae of the ancient Odessos, Drone-operator: Ivan Atanasov, 2014

In 2013, the studio already had built the basic model of the virtual reconstruction according the handmade sketches and drafts of Prof. S. Boyadzhiev, combining them with the twodimensional geodetic survey of the terrain of the ruins of the excavated thermae. At this stage of work on the virtual reconstruction of the interiors there was a need to insert the digital 3D models of the ancient statues from this archaeological site, exposed in the Regional Museum of History - Varna.

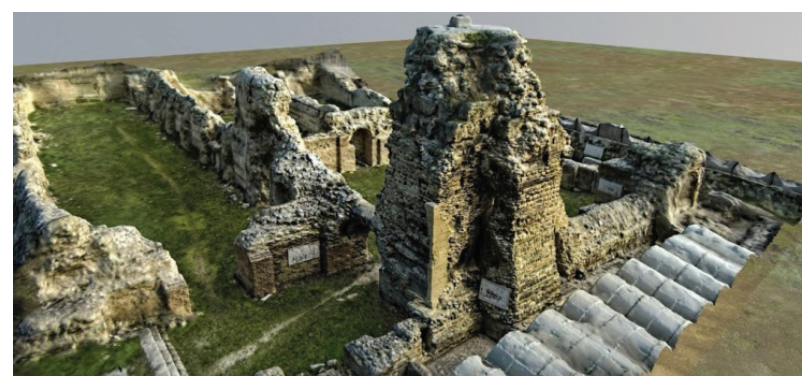

Fig. 5. Digital model of the highest survived part of the ruins of the Imperial Roman Thermae of the ancient Odessos, done during the testing of the software Memento by the trainee Deyan Kostov,

Drone operator: Ivan Atanasov, 2014

The digital models of the statues in 2013 were made with 123D Catch software using the digital files produced by Sony Cyber-Shot DSC-W220 
digital camera with 12.1 megapixels. From these options: to clean the background after the model is ready, or before, both of them were tried. In 2013 the team chose to do this before uploading the photos to the program. Fig. 1 shows the removed backgrounds of the photos of the statues that were used as an incoming 2D auto-processing material with the software 123D Catch in 2013. However, working with the newer versions of the program, testing Memento (subsequently released under the trade name ReMake), and with the next version (called ReCap), the team empirically came to the conclusion that the backgrounds help to build a model with a higher quality (Fig. 3, Fig. 5, Fig. 21).

Generally, there are obtained details with a better quality in the cases when the whole objects are processed with their surrounding environment and then the unnecessary parts are removed. The models shown at Fig. 5 and Fig. 6 have several million surface elements for the so called "tower". The streets and the buildings were subsequently removed from the digital 3D model. The rest of the model was not of a good quality as it was not a subject to the drone survey. The drone route was a helical flight around the subject with automatic shooting every few seconds. The photographs were taken both during the upward flight and the landing.

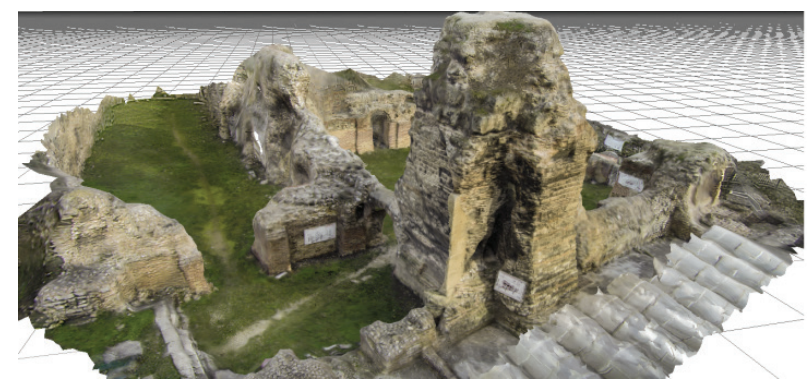

Fig. 6. Digital model of the highest survived part of the ruins of the Imperial Roman Thermae of the ancient Odessos, done by software Zephyr by the trainees Antonio Diana and Ivano Signore, Drone operator: Ivan Atanasov, 2014

This first trial of the studio to capture the real ruins three-dimensionally in 2014 by means of photogrammetry revealed the problem that the height of the basic model, assembled in 2013, did not fit to the expected height of the building.
In 2019 , the team decided to try out up-todate software for continuing work on the site this year. The two Italian architects Ivano Signore and Antonio Diana, interns at Architectural Spies, tried several software updates (Agisoft Phothoscan, Visual SFM, Open Drone Map, PrecisionHawk 3D Map, DroneDeploy 3D Mapping, Pix4D Mapper, Zephyr). The team decided to continue the work done so far with 123D Catch, ReMake (Memento), and ReCap with the Italian software Zephyr. The second decision was the separately produced 3D models of different parts of the huge archeological site to be assembled through the software for 3D modeling Blender. Into the work had been involved the intern Ahmet Kizil, a mechatronics engineer. In 2019 the drone surveys were being conducted by the architect Orlin Perfanov, who was working on the Roman thermae project since its beginning. The new drone operator Ahmet Kizil did all the drone works in the summer season of the same year.

At the beginning of the work in 2019, new terrestial photo material was prepared: from the level of the ancient Odessos and from the pedestrian higher level of the streets surrownding the archaeological site.

New drone photos were also prepared. Using all this cumulative material collected by remote survey from different devices was impossible. The program was selecting only the same type of image files taken with one type of device. The team wasted a lot of time trying to solve the problem of unifying the metadata of the files taken by different devices (camera, several smartphones, used at low levels and high levels with simple selfie sticks and also by the made by the engineer of mechatronics A.Kizil telescopic device for terrestial surveys with a height of $4 \mathrm{~m}$, as well as a drone camera for aerial photography). The external collaborator of the team Aleksandar Pavlov tried several converters for unification of metadata: Exif Pilot, Brightworks Image Convertor, AVS Image Convertor, but none of them gave a satisfactory result. When did a remote survey of another (but not archaeological) site, later than the beginning of Roman Thermae, the team concluded that the problem with the metadata of the collected visual material from the archaeological site did not differ from the problem 
with the metadata of the pictures taken with different devices. The example, above spoken about, was a building from the beginning of the 20th century (Fig. 7, Fig. 8), on which the both street facades had just been renovated and the facades in the yard yet not renovated. Snapshots were taken from the human horizon and from two high levels by two different brands of smartphone cameras. The software automatically selected as compatible all photos of the unrepaired facades in the courtyard taken by both cameras, despite the fact that the building was shot around with the same percentage of overlapping. The software automatically rejected (could not recognize) the photos from the corners with images of restored and unrestored facades.

In the further discussion of the problem, it was decided that instead of photographs, the visual data to be captured by aerial videos. The drone of Architectural Spies, operating in 2019 has the following features: Xiaomi Mi Drone 4K, Camera: 4K Video; 12.4MP Photos, Image Resolution: 4000 x 3000, Video: 3840 x 2160p 30 fps; 2560 x 1440p 30 fps; 1920 x 1080p 100/60/30 fps, FPV (real-time video) FullHD directly to smartphone or tablet, $360^{\circ}$ flip.
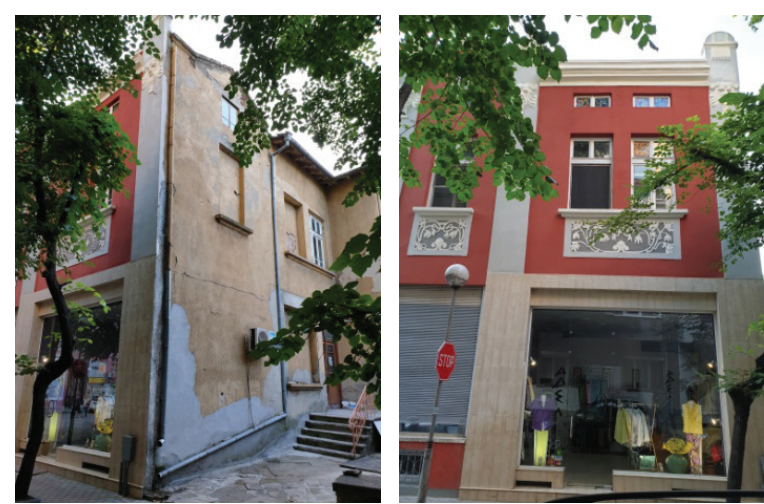

Fig. 7-8. Example about the problem with the metadata: photos at the corner with renovated and not renovated façade walls of the building,

28 Dragoman St/13 Bdin St, Varna

Photos: Antonio Diana and Ivano Signore, 2019

This type of drone has a flight duration of 26-27 minutes, significant for this type of aircraft, which means that since the route is short (the drone can fly as much as $4 \mathrm{~km}$ ), it is possible to move and hover above the surveyed site without risk for up to 20 minutes as its landing area is adjacent.

As it was already said, the team had, from the work in 2014 , excelent quality aerial photos of the highest part of the ruins, taken by a complicated to control two-way screw drone flying (Fig. 5). Before creating a new model of this part of the archaeological site, a second model was created with the old photo material from 2014, but with the new, different software. The reason for choosing Zephyr, instead of ReCap, to continue the work was because when switching from ReMake to ReCap, the option to run it on one's own machine was removed, i.e. the whole process had to be processed in the cloud.

The original plan for aerial photography was to fly gradually, stopping the drone one, two, or several times above each hall, depending on its area and pointing the camera at an angle of about $45^{\circ}$ to make a full $360^{\circ}$ rotation. With this method of shooting, the result turned out to be a lack of processing data in the middle of the halls, where the drone had stopped rotating its camera. The frist drone works in 2019 were done by the architect Orlin Perfanov in two ways - photo and movie files. After taking over these works by the engineer Ahmet Kizil, it was decided to fly only gradually, with a serpentine-shaped route over all the archaeological site. This decision was made as a result of the approaching the software Zephyr by the Italian interns Ivano Signore and Antonio Diana. Also important was the shooting time. The flight activities in 2019 took place early in the morning around the date of the summer solstice. The first videos done by the architect Orlin Perfanov were made between 7 a.m. and 8 a.m. and despite the impression of the enhanced volume and picturesqueness of the produced by them $3 \mathrm{D}$ model, the conclusion was that doing a remote survey in this hour is technically problematic. The article of Dr. N. Stamatova from 2018 cited in the bibliography (3) comments on the recommended daylight in the preparation of an ortho-photo and gives an example not listed here. A similar example from 2019 could bee seen on Fig. 9 for the model of the central part of the Roman Thermae. 


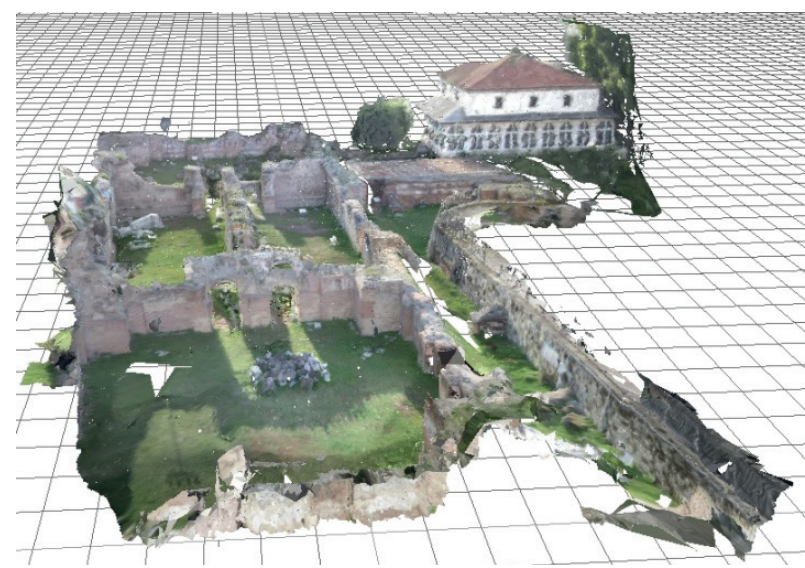

Fig.9. 3D model of the central part of the thermae (frigidarium, tepidarium, caldarium) produced from the digital data of aerial surveys between 7 a.m. and 8 a.m.in the summer of 2019

Subsequently the time of the aerial survey was changed to an earlier one, allowing only the highest part of the thermae to be directly illuminated by sunlight. The time was changed to start at 5:30 and finish at 6:15 in the morning, while the ruins were not directly illuminated by the sun's rays. The compromise was done only for the highest part (the so-called by the locals "tower") but no more than about a meter and a half (Fig.15).

In the summer of 2019, separate parts of the three-dimensional model were made, prepared for their mutual assembly, complemented with smaller fragments and details. Several powerful machines are to operate together, as each of the produced parts has a surface of more than a million elements. It was important for the team to achieve a high quality in the digitization of the existing ruins that would be of help to refine the height component of the original 3D model of the digital reconstruction, which was mentioned in the beginning (Jeleva-Martins D., 2013 [12]).

In regard to the preciseness of the produced digital models, there could be compared examples of the view of random frames of the remote drone surveys (Fig.13) with the fragments from the digital 3D models, constructing the view from the virtual camera (Fig.14).

The team intends to use as volumetric targets for activation of an Augmented Reality application, respresenting the digital reconstruction the studio works on, a set of character points of the digital 3D model of the ruins done in the studio, fitting onsite to characteristic points of the real ruins. As a result of the recognition of the target, the model of the digital reconstruction will appear on the screens of the preferred devices, superimposed on the image of the real ruins, visible through the camera of the devices. To date, the assembly of the produced in 2019 parts of the digital model of the existing ruins has just begun.

The summer season of 2019 was very fruitful for the studio in regard to the digitization of different objects of the cultural heritage of the city of Varna. For some years the studio has been following its ambition to be placed in the niche of Augmented Reality content producers in Europe. This goal is in a way related also to the Virtual Reality technology because some of the results of the Augmented Reality production could be shown not only onsite (that is obligatory for the AR).

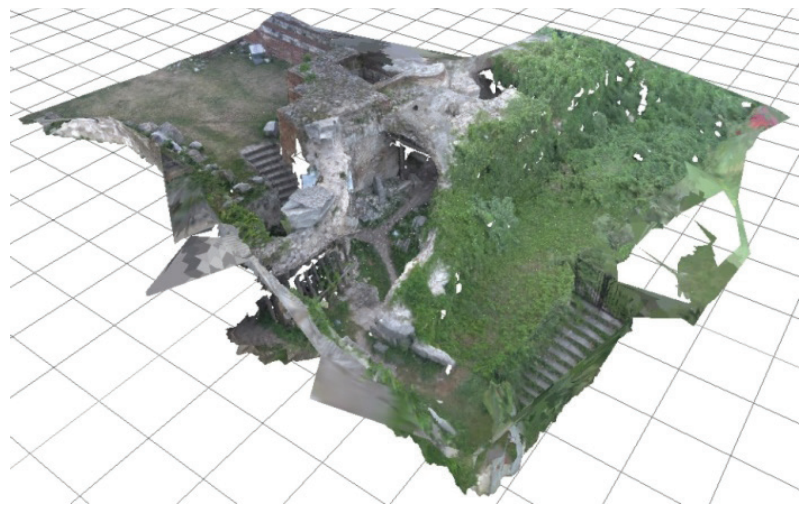

Fig.10. 3D model of a part of the caldarium and the corridor at the hypocaustum, 2019

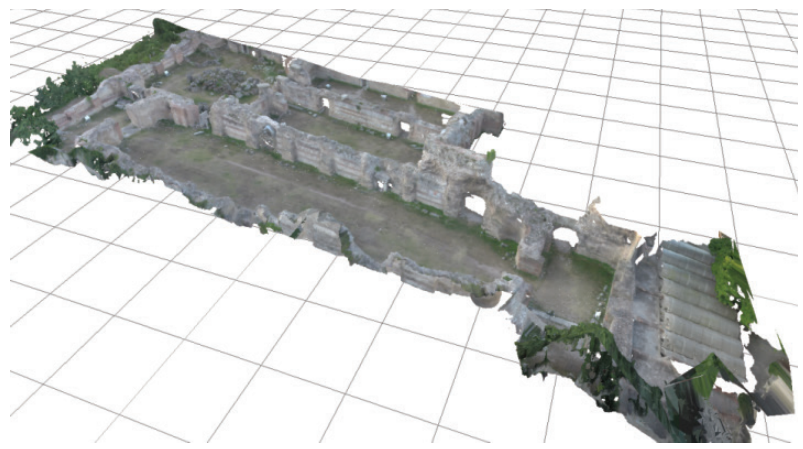

Fig.11. 3D model of the apodyterium (13), the East vestibulum (13), and the frigidarium. The fragment on Fig. 14 is from this model, 2019 


\section{КУЛТУРНОТО НАСЛЕДСТВО НА ВАРНА И ЧЕРНОМОРСКИЯ РЕГИОН}

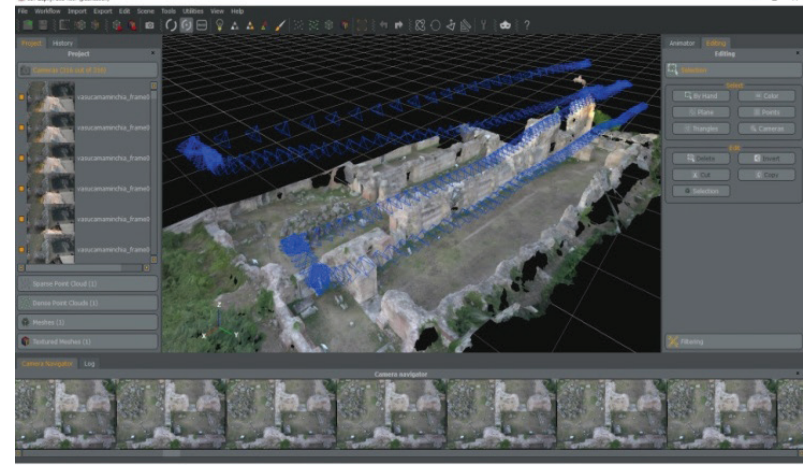

Fig.12. Print screen at the dectop of Ahmet Kizil during his work on the model of the apodyterium (13) with software Zephyr, 2019

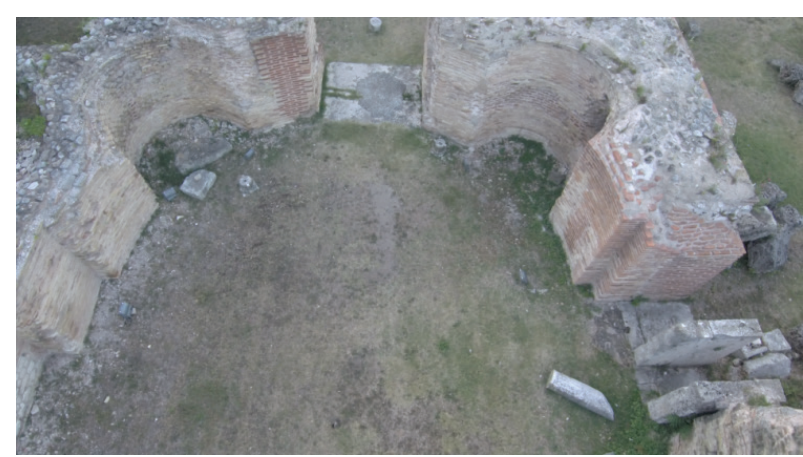

Fig.13. The apses and the entrance at the East wall of the apodyterium - a frame from a video.

Drone operator: Ahmet Kizil, 2019

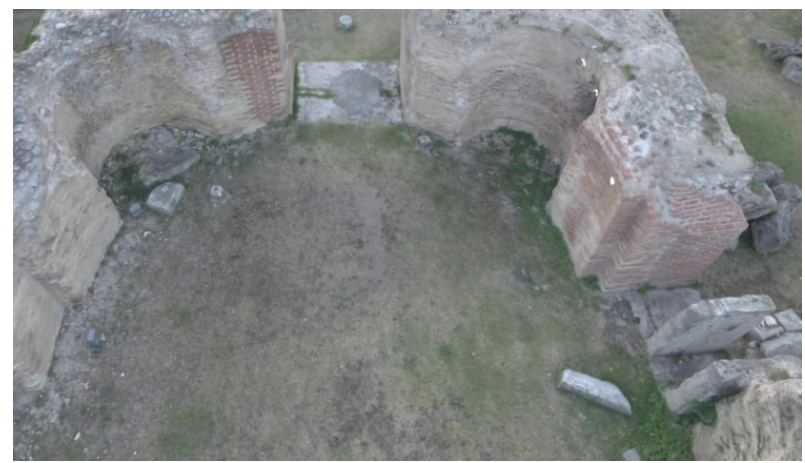

Fig.14. A fragment from the $3 D$ model from the position of the video frame, shown on Fig. 13 3 D model: Ahmet Kizil, 2019

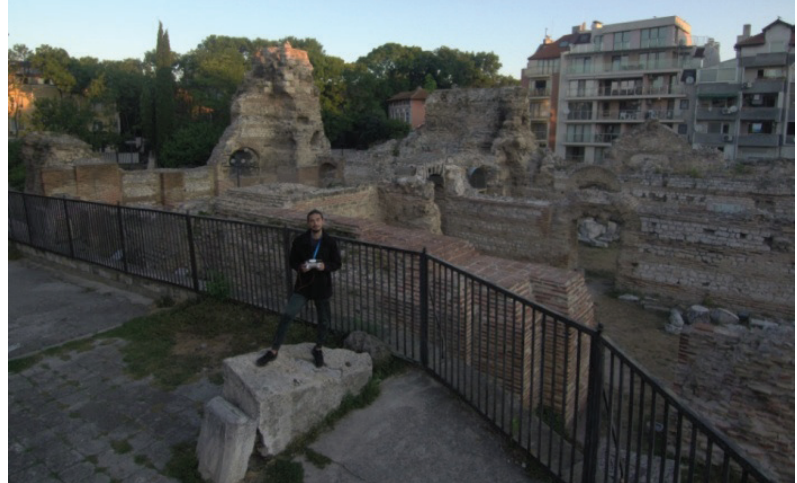

Fig. 15. Drone operator Ahmet Kizil at the landing of the drone at 6:15 a.m. in the summer of 2019

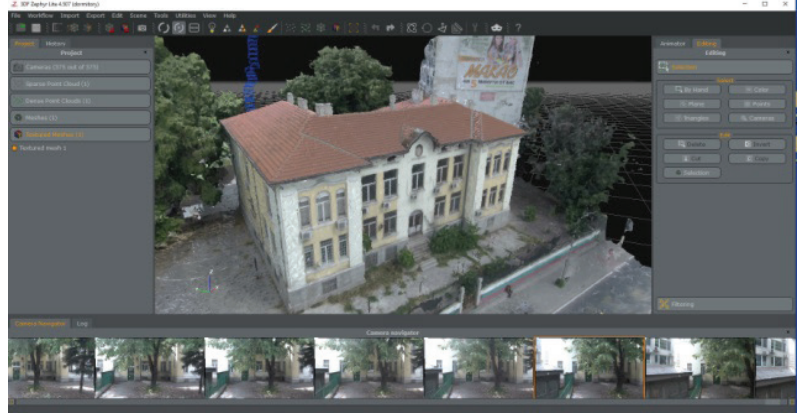

Fig.16. 3D model of the orphanage "Nadezhda" Zephyr Desktop of Jakub Olszewski, 2019 Drone operator: Ahmet Kizil

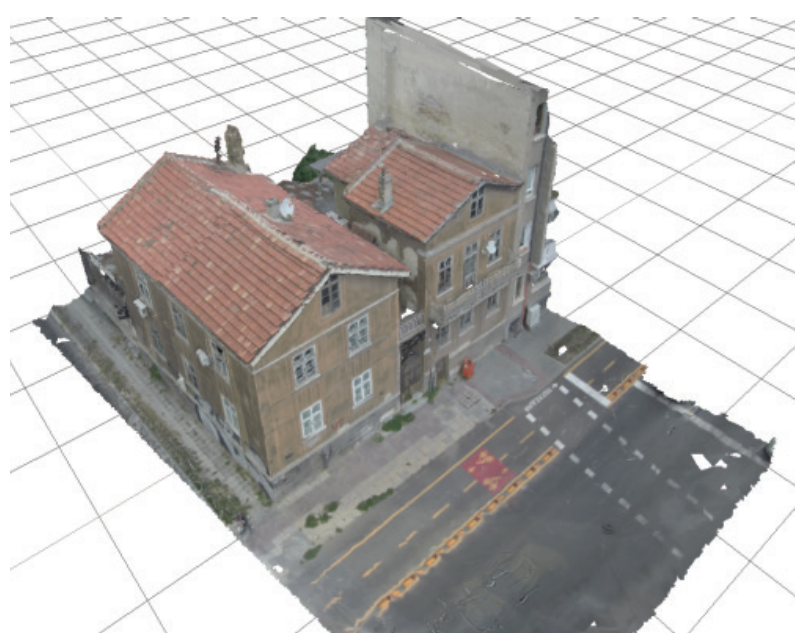

Fig.17. 3D model of twin houses on Saborni St. Zephyr Desktop of Jakub Olszewski, 2019 Drone operator: Ahmet Kizil 


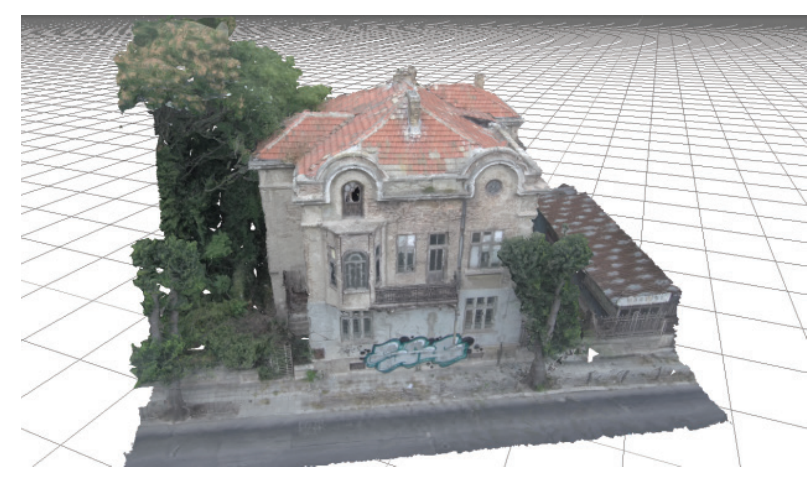

Fig.18. 3D model of a house at Rachinska St. Zephyr Desktop of Jakub Olszewski, 2019 Drone operator: Ahmet Kizil

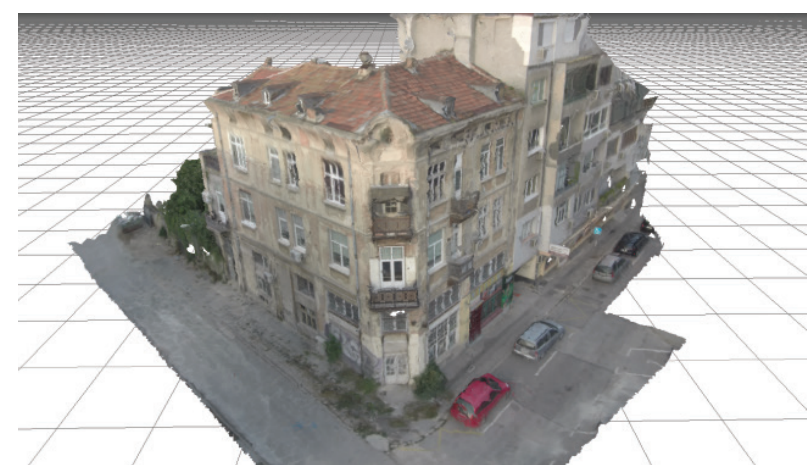

Fig. 19. 3D model of a building at Dunav St. Zephyr Desktop of Ahmet Kizil, 2019 Drone operator: Ahmet Kizil

A package of about dozen other digital 3D models of buildings in Varna was done also to create a database for an Augmented Reality application the studio works on with a work title "The Non-Surviving Buildings: Varna".

There is no other city or town in Bulgaria losing such a big part of its cultural heritage every year, the specialists in the National Institute of Cultural Heritage at the Ministry of the Culture of Republic of Bulgaria shared with Dr. N. Stamatova some years ago. The author will not discuss in this publication (let other specialists do it) the socio-economical reasons for the removal of buildings in the city of Varna from beginning of the $20^{\text {th }}$ century from the list of the cultural heritage with the aim to be demolished. What the studio Architectural Spies aims with its AR application "The Non-Surviving Buildings: Varna" is for the locals and the tourists when walking on the streets of the city to be able to see the buildings that have disappeared forever from the cityscape of Varna at their former places.

The staff of the studio reacts immediately in case of information of urgency. Sometimes even does extra work as a result of misleading data, as it happened in the case of creating the model of the orphanage "Nadezhda" ("Hope") (Fig.16), produced during the holidays. The first business day of the following week the studio received an answer from the municipality that the 22-story skyscraper, planned at the place of the orphanage, had not been approved by the municipal authorities and the reason for emptying the building was a future renovation.

We considered too that the statue "Mercury over an Eagle" (Fig.20,21,23,24) of the eminent sculptor Kiril Shivarov at the attic of the former Sofia Bank in Varna had to be digitally captured immediately before the forecasted winter storm. Fortunately, only the last two digits from the year of its creation, 1922, fell down.

The credo of the professionals and the interns at the studio is that it is always better to do unnecessary digitizing work than to miss the building's demolishing. 

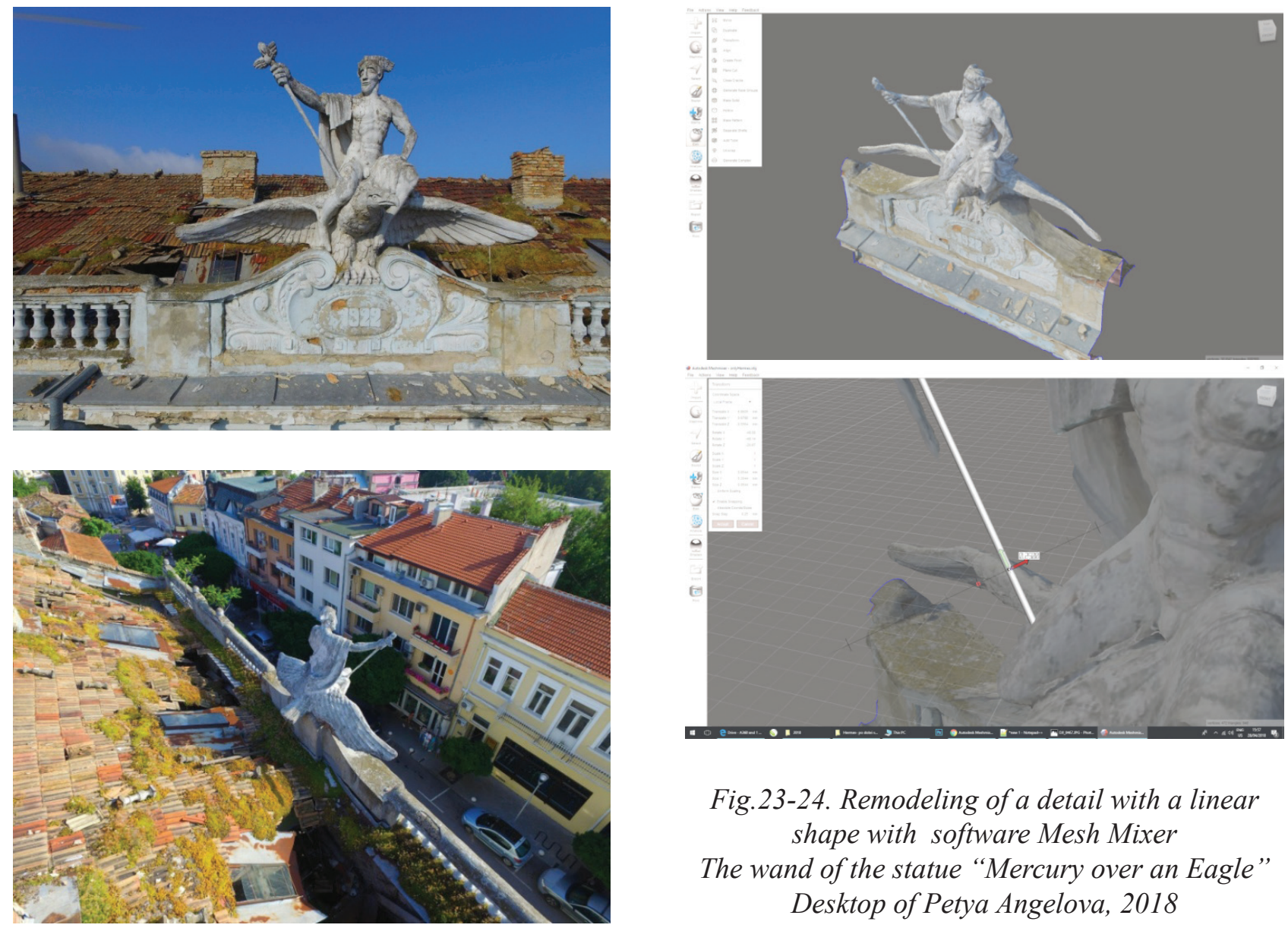

Fig.23-24. Remodeling of a detail with a linear shape with software Mesh Mixer

The wand of the statue "Mercury over an Eagle" Desktop of Petya Angelova, 2018

Fig.20-21. Aerial photographies of the statue "Mercury over an Eagle", used for its 3D model Drone operator: Rostislav Serbezov, 2017
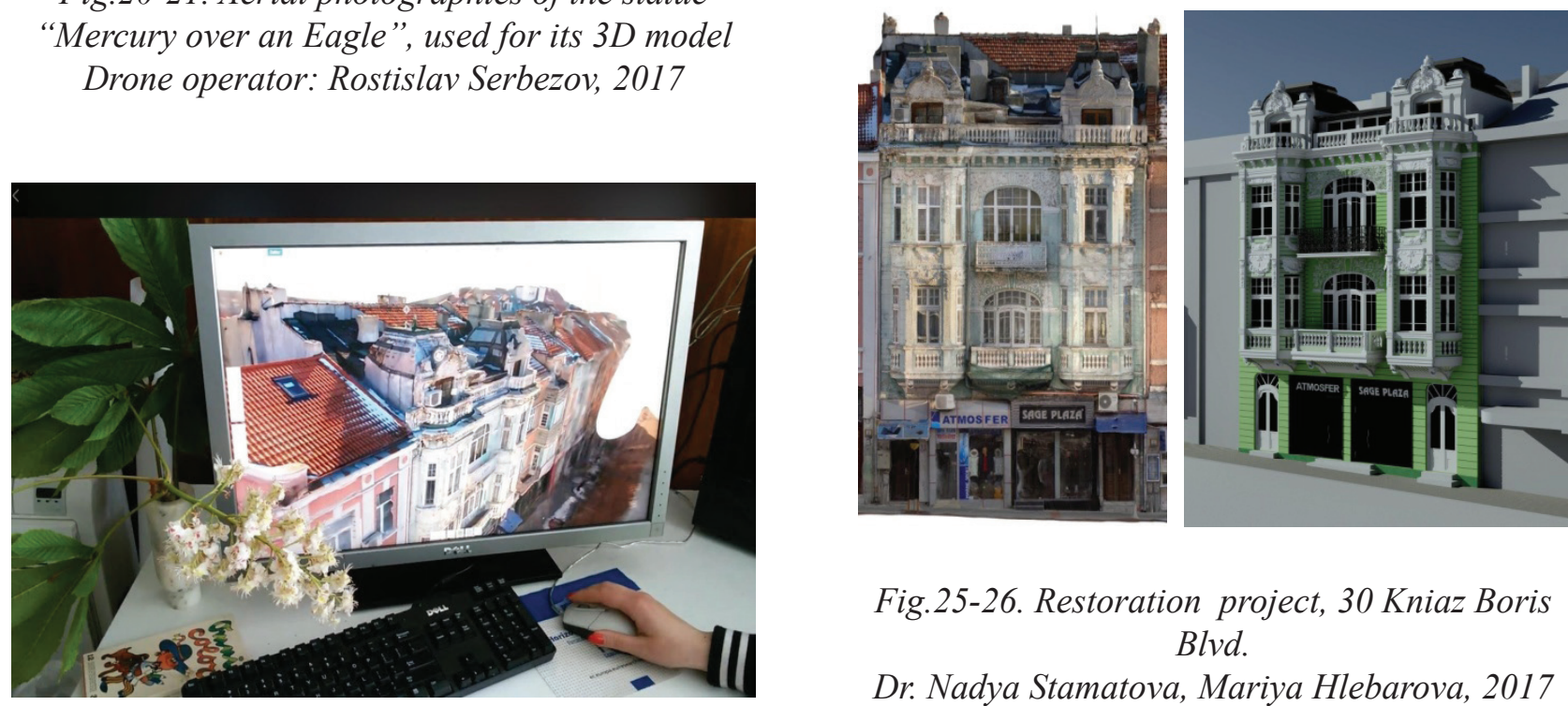

Fig.25-26. Restoration project, 30 Kniaz Boris Blvd.

Dr. Nadya Stamatova, Mariya Hlebarova, 2017 Ortho-photo, ReMake: Vasiliya Staykova $3 D$ model, AutoCAD: Anani Yankov

Fig.22. Restoration project, 30 Kniaz Boris Blvd. Dr. Nadya Stamatova, Mariya Hlebarova, 2017 Demonstration: 3D model with softwate ReMake Details, ReMake+Blender: Esin Yuseinova Desktop of Vasiliya Staykova, 2017 facebook.com/ArchitecturalSpaceVarnal videos/744933522345377/ 

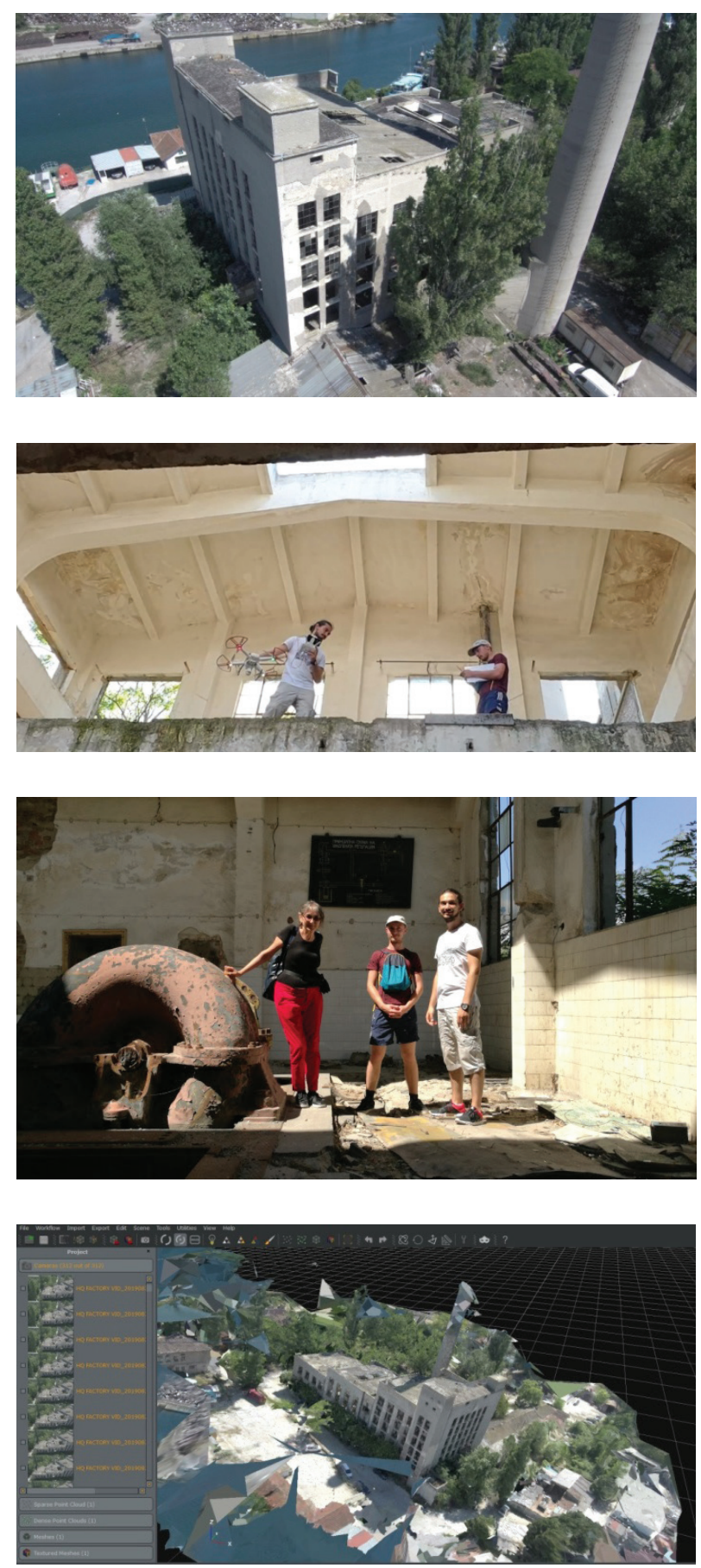

Fig.27-30. Exterior and interior remote survey and $3 D$ modeling with Zephyr and Blender of the

Thermal Power Plant "Yanko Kostov" Drone operator: Ahmet Kizil

Terrestrial Surveyor: Jakub Olszewski $3 D$ model: A.Kizil and Jakub Olszewski

Interior and exterior remote survey and a 3D model of an industrial archaeology site were done in 2019 for the project of D. Hristova for its renovation as a museum of the industry [2], [8], [9],
[10] (Fig. 27-30).

During the work on the application about the non-surviving buildings, the team came to the idea that it would also be good to show by means of AR technology the positive examples of well-restored or reconstructed old buildings. The team started to capture remotely terrestrial and aerial data for buildings that are in evidently bad condition. Examples of such already digitized buildings are shown on Fig.16-19.

Another example is the digitizing of the building shown on Fig.7-8 and Fig.31. It is one of the virtual demonstration sites of the H2020 project BIM-SPEED (Harmonized Building Information Speedway for Energy-Efficient Renovation) (15). The planned work had to be only AR/VR demonstrations. Surprisingly, the ownership of the shops was changed and the project for façade restoration, designed in the past years by Dr. N.Stamatova and M. Hlebarova was realized in the summer of 2019. The studio Architectural Spies, leading the AR/VR task in the project BIMSPEED, presented the content of the demonstrations in a higher complexity than it was planned.
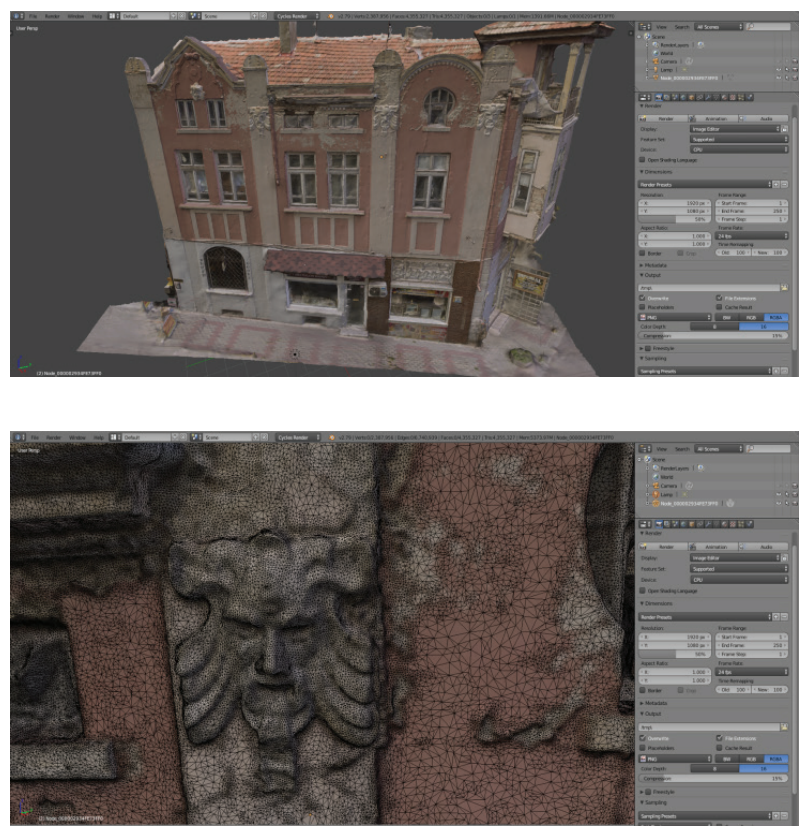

Fig.31-32. 3D model of a building in Varna located on 28 Dragoman St, combining in blender results from ReCap and Zephyr 3D model: Ahmet Kizil, 2019 


\section{References:}

1. Stamatova N., 2019: Digitization of the Archaeological Site of the Imperial Roman Thermae of the Ancient Odessos - Part I, Digitization of the Cultural-Historical Heritage, National Center of Digitization of the Balkans, Black Sea Region and Caucasus, v.2, DIOS, Sofia (C) 2019 ISBN 978-954-8405-71-3, ISBN 978-9548405-72-0 DOI: $10.13140 / \mathrm{rg} .2 .2 .14563 .91683$

2. Stamatova N., 2019: Digitization of Industrial Archaeology: the Thermal Power Plant Yanko Kostov in the South Industrial Zone of Varna,Digitization of the Cultural-Historical Heritage, National Center of Digitization of the Balkans, Black Sea Region and Caucasus, v.2, DIOS,Sofia,C2019 ISBN 978-954-8405-71-3 ISBN 978-954-8405-72-0

\section{DOI: $10.13140 / \mathrm{rg} .2 .2 .22952 .52487$}

3. Stamatova N., 2018: Preparation of 3D Models of Archaeological Sites, Buildings, Fragments and Details through Automatic Transformation of 2D Data. Examples of the Territory of the City of Varna. Use of the Method for Preparing a Database for Development of Software Applications for Augmented Reality., Digitization of the Cultural-Historical Heritage, National Center of Digitization of the Balkans, Black Sea Region, and Caucasus, v.1, pp.198-202 DIOS, Sofia, (C) 2018 ISBN-978-954-8405-69-0, IBSN-978-954-8405-70-6

4. Stamatova N., 2018: Digital 3D model of a statue of Nike (No1) from the Imperial Roman Thermae of the Ancient Odessos, DIOS, Sofia C2018 ISBN-978-954-8405-70-6 DOI: $10.13140 / \mathrm{rg} .2 .2 .22358 .70720$

5. Stamatova N., 2018: Digital 3D model of a statue of Nike (No2) from the Imperial Roman Thermae of the Ancient Odessos, DIOS, Sofia C2018, ISBN-978-954-8405-70-6 DOI: $10.13140 /$ rg.2.2.26553.01121

6. Stamatova N., 2018: Digital 3D model of a statue of Heracles from the Imperial Roman Thermae of the Ancient Odessos, DIOS, Sofia (C)2018 ISBN-978-954-8405-70-6 DOI: $10.13140 / \mathrm{rg} .2 .2 .33263 .89769$

7. Dovramadjiev, T., 2018: Digitalization of Ancient Sculpting Models and 3D Design Using Photogrammetry Methodology, 6th International Scientific Conference on Advanc- es in Mechanical Engineering (ISCAME 2018) 11-12 October, 2018 Debrecen, Hungary, DOI: 10.21791/IJEMS.2019.1.57, ISBN 978-963-490051-1 International Journal of Engineering and Management Sciences(IJEMS) v.4 No.1, (C) 2019

8. Hristova D., Grancharov P., 2015: Significant Buildings and facilities along the Bulgarian Black sea Coast in the XIX - XX Century, $7^{\text {th }}$ International Scientific Conference Architecture, Civil Engineering-Modernity, 28-30 ${ }^{\text {th }}$ May2015, Varna, ISSN 2367-7252,pp.78-90

13. Христова Д., Грънчаров П., 2012 Музей на науката и индустрията във Варна или още нещо за Индустриалната археология в България, Първа градска конференция на Варненско историко-архитектурно дружество (ВИАД) , изд. къща „Стено“, ()2012

10. Hristova D., 2013, Contemporary Museum Buildings - Adapatation of Existing Industrial Buildings and Equipment, An Annual Book, v. XIX, 2013, VFU, Varna ISSN 1310-800 X, pp.319-329 (C) 2013

11. Ilieva J., 2013: Secession Motifs in Varna Architecture from the Early $20^{\text {th }}$ Century, $6^{\text {th }}$ International Scientific Conference Architecture, Civil Engineering-Modernity, VFU, 28-30 $0^{\text {th }}$ May 2013,Varna, ISSN 1314-3816 pp.269-278 (C) 2013

12. Желева-Мартинс Д., 2013: Биографичен разказ за проф. арх. Стефан Бояджиев, сп. Архитектура, бр.3, 2013, стр.48-58 https://www.academia.edu/6975223

13. Бояджиев С., 2006: Roman Baths (Thermae) in Bulgarian Lands II-III C.A.D., Archaeology of the Bulgarian Lands, volume II, IVRAY-Sofia, pp.37-79 ISBN-954-9388-02-6(v. II) C2006

14. architecturalspies.com/internship

15. www.bim-speed.eu/en

contacts:

Nadya Stamatova, Ph.D., M.Arch. nadya.stamatova@gmail.com orcid.org/0000-0002-5265-7958 researchgate. net/profile/Nadya Stamatova ind ep end ent. ac ad e mia.edul NadyaStamatova bg.linkedin.com/in/nadyastamatova 